Patricia Gomes Ferreira da Costa ${ }^{1}$

Francisco José de Castro Moura Duarte ${ }^{1}$

Francisco de Paula Antunes Lima²

Nora de Castro Maia ${ }^{3}$

Adriana Nunes Araújo ${ }^{4}$

\section{A efetividade de metodologias de diagnóstico rápido em ergonomia em plataformas offshore: revisitando o conceito de modo degradado de funcionamento}

\author{
The effectiveness of rapid ergonomics diagnostic methodologies \\ applied to offshore platforms: revisiting the concept of degraded \\ mode of operation
}

\footnotetext{
${ }^{1}$ Universidade Federal do Rio de Janeiro, Instituto Alberto Luiz Coimbra de Pós-Graduação e Pesquisa de Engenharia, Programa de Engenharia de Produção. Rio de Janeiro, RJ, Brasil.

${ }^{2}$ Universidade Federal de Minas Gerais, Departamento de Engenharia de Produção. Belo Horizonte, MG, Brasil.

${ }^{3}$ Petrobras, Centro de Pesquisas e Desenvolvimento Leopoldo Américo Miguez de Mello. Rio de Janeiro, RJ, Brasil.

${ }^{4}$ Petrobras, Unidade de Operações de Exploração e Produção da Bacia de Campos. Rio de Janeiro, RJ, Brasil.
}

Contato:

Patricia Gomes Ferreira da Costa

E-mail:

patriciagfc@gmail.com

O trabalho não foi baseado em tese.

O trabalho não foi apresentado em reunião científica.

Os autores declaram não haver conflitos de interesses e que o trabalho não foi subvencionado.

\section{Resumo}

Introdução: plataformas offshore enfrentam crescentes demandas de manutenção, com um quantitativo fixo de trabalhadores. Com o tempo, ocorre a degradação progressiva das instalações, sendo necessárias estratégias diferenciadas para recuperar a integridade operacional. Objetivo: apresentar como uma Metodologia de Diagnóstico Rápido (MDR) em ergonomia foi elaborada para avaliar um conjunto de plataformas e revisitar o conceito de Modo Degradado de Funcionamento, quanto a segurança e confiabilidade operacional. Método: a MDR foi construída em quatro etapas e aplicada em 12 plataformas. Para cada uma, foram retraçados os processos históricos de seu modo de operação atual. Resultados: esta MDR permitiu revelar princípios gerais para sistematizar situações que devem melhorar e compreender processos amplos, que levaram ao acúmulo de condições ergonomicamente inadequadas, e recuperar parte da experiência acumulada pelas equipes embarcadas. A chave foi a preparação para os embarques, baseada na experiência dos ergonomistas e dos trabalhadores onshore e offshore. Conclusão: diagnósticos rápidos podem contribuir para reverter processos crônicos de degradação ao revelarem a visão geral das condições de vida e trabalho a bordo, as trajetórias singulares das plataformas e a contribuição positiva dos trabalhadores, colocando em debate mudanças e ações necessárias à inflexão de um dado percurso.

Palavras-chave: trabalho offshore; indústria petroquímica; análise ergonômica; diagnóstico rápido em ergonomia; modo degradado de funcionamento.

\begin{abstract}
Introduction: offshore platforms face increasing maintenance demands with fixed amount of workforce. Over time, the progressive deterioration of installations can be evidenced leading companies to adopt distinguished strategies to recover operational integrity. Objective: to present the development of a Rapid Ergonomics Diagnostic Methodology (REDM) to evaluate a group of platforms and revisit the concept of degraded mode of operation regarding safety and operational reliability. Method: the REDM was built in 4 stages and applied in 12 platforms of the studied company. For each one, the historical processes of its current operating mode were retraced. Results: this REDM allowed revealing general principles to systematize situations that should be improved, understanding broad processes that led to the accumulation of ergonomically inadequate conditions and recovering part of the experience accumulated by the embarked teams. The key was the preparation for shipments based on the ergonomics team and workers experience, both, onshore and offshore. Conclusion: REDMs can help to reverse chronic degradation processes by providing an overview of on boardwork and living conditions, the platforms' unique trajectories and the positive workers' contribution, discussing changes and necessary actions for a given route inflection.
\end{abstract}

Keywords: offshore work; petroleum industry; ergonomics analysis; rapid ergonomics diagnostic; degraded mode of operation. 


\section{Introdução}

\section{Cenário atual do setor petroleiro: novas demandas para a ergonomia}

Após o acidente na plataforma Deepwater Horizon $^{5}$, no campo de Macondo, no Golfo do México, quando foram registradas as mortes de 11 pessoas e o vazamento de 4,9 milhões de barris de petróleo, foram intensificadas, no Brasil, as fiscalizações in situ de plataformas offshore (NATIONAL COMMISSION ON THE BP DEEPWATER HORIZON OIL SPILL AND OFFSHORE DRILLING, 2011; ESPINOLA, 2013). Uma das ações foi a instituição do projeto nacional de inspeção em unidades marítimas de produção e exploração de petróleo e gás, chamado de Operação Ouro Negro (ESPINOLA, 2013). Nesse projeto, técnicos e fiscais dos órgãos reguladores ${ }^{6}$ embarcam juntos para realizar inspeções das condições operacionais das plataformas e das condições de trabalho. $\mathrm{O}$ foco central das inspeções são as condições relacionadas à conservação e à integridade das instalações e dos equipamentos. Para continuar em operação, as plataformas devem atender aos requisitos de uma ampla legislação - ambiental, marítima e trabalhista.

Atualmente, a Bacia de Campos, com plataformas com mais de 20 anos de operação, tem sido alvo constante dessas inspeções (CHAMBRIARD, 2014), que podem levar a interdições temporárias da produção, se detectadas situações consideradas críticas do ponto de vista da integridade operacional, das instalações e das condições de trabalho e de vida no ambiente offshore. Esse panorama, de modo geral, reforça o interesse por estudos sobre o trabalho offshore. "Compreender o trabalho para transformá-lo" (GUÉRIN et al., 1997) é uma tarefa para a qual a ergonomia encontra-se tradicionalmente aparelhada. No entanto, essas fiscalizações trouxeram novas demandas, que exigiram inovações metodológicas e o tratamento de novos problemas:

1) Como realizar avaliações ergonômicas em grande escala sem perder a profundidade do conhecimento sobre a atividade de trabalho, que não se deixa apreender de imediato, requerendo normalmente observações longas e entrevistas em autoconfrontação? ${ }^{7}$

2) O que se pode concluir em relação à confiabilidade de uma unidade de produção, a partir de indicadores visíveis de inadequações materiais e ergonômicas? Inadequações menores, facilmente observáveis, são prenunciadoras de riscos mais graves? ${ }^{8}$

3) Quais as origens das atuais condições de trabalho e do modo de funcionamento das plataformas? Podem-se atribuir essas situações ao clássico conflito entre saúde/segurança e produção, ou a ação do tempo, a obsolescência técnica, seria a principal responsável pela alteração do funcionamento nominal das plataformas?

A rigor, essas demandas e esses problemas não são estritamente novos no campo da ergonomia, mas ainda não foram, a nosso ver, adequadamente resolvidos. Neste artigo, não pretendemos dar uma resposta geral a essas questões, mas buscamos dois objetivos mais específicos:

1) Mostrar como uma Metodologia de Diagnóstico Rápido (MDR) em ergonomia foi desenhada, a partir da experiência prévia da equipe, para dar uma resposta eficaz às demandas de avaliação ergonômica em grande escala, em especial sob

\footnotetext{
5 A British Petroleum, empresa reponsável pelo poço de Macondo, no Golfo do México, e a Halliburton, que gerenciou a operação de vedação do poço, foram responsabilizadas pelo desastre, assim como a Transocean, proprietária da Deepwater Horizon (NATIONAL COMMISSION ON THE BP DEEPWATER HORIZON OIL SPILL AND OFFSHORE DRILLING, 2011).

6 Marinha do Brasil, IBAMA (Instituto Brasileiro do Meio Ambiente e dos Recursos Naturais Renováveis), ANP (Agência Nacional do Petróleo), ANVISA (Agência Nacional de Vigilância Sanitária), MPT (Ministério Público do Trabalho), MTE (Ministério do Trabalho e Emprego) e SRTE (Superintendência Regional do Trabalho e Emprego, do Ministério do Trabalho).

7 Além de a atividade ser invisível, ao ocupar o espaço ineliminável entre o prescrito e o real, dá-se também na forma de ações situadas, inseparáveis do contexto em que acontecem, incluindo o trabalhador que a realiza, com sua experiência e história singulares. Sobre a análise em profundidade da ação e cognição situadas, ver Theureau (2014).

8 Na área de segurança, é conhecida a pirâmide de acidentes (dita de Frank Bird, mas que remonta a H. W. Heinrich), que estabelece uma proporcionalidade entre comportamentos críticos, incidentes, perdas materiais, lesões leves e acidentes graves. No entanto, essas relações causais são antes pressupostas do que demonstradas de forma rigorosa. Anderson e Denkl (2010, p. 1) dizem que: “Heinrich's principle works only when applied to a large number of combined hazards and activities. [...] ratios postulated by Heinrich do not work when applied to specific activities. The result is that companies tend to over focus on the easily identifiable risks which follow the Heinrich triangle but are often nonfatal, at the cost of losing sight of activities that have the potential of a fatal outcome", isto é: "O princípio de Heinrich funciona apenas quando aplicado a um grande número de riscos e atividades combinadas. [...] As proporções postuladas por Heinrich não funcionam quando aplicadas a atividades específicas. O resultado é que as empresas tendem a focar mais nos riscos facilmente identificáveis, que seguem o triângulo de Heinrich, mas, muitas vezes, não são fatais, sob pena de perder de vista as atividades que têm potencial de desfecho fatal” (tradução livre dos autores).
} 
a forte restrição do tempo de observação ${ }^{9}$, e quais resultados foram obtidos;

2) Recolocar em questão o conceito de Modo Degradado de Funcionamento (MDF) (WISNER, 1989), quanto à valoração negativa de aumento de riscos operacionais e de redução da confiabilidade das instalações.

\section{Métodos}

\section{O desenvolvimento da MDR para a aplicação em um conjunto de plataformas de petróleo}

De modo a responder aos objetivos propostos, a abordagem metodológica de avaliação ergonômica desenvolvida (COSTA, 2014) foi conduzida em dois ciclos: o primeiro, de desenvolvimento e validação; e o segundo, de consolidação e aplicação. No primeiro ciclo, foram visitadas seis plataformas. O segundo ciclo, iniciado em novembro de 2012, tem duração estimada de três anos e a abordagem de avaliação aplicada a cerca de 30 plataformas. Até abril de 2015, foram realizadas avaliações em 19 plataformas offshore, o que conduziu a aprimoramentos posteriores na MDR inicialmente desenvolvida. Para este artigo, foram considerados os estudos das 12 primeiras unidades estudadas (realizados até dezembro de 2013).

O número de dias por embarque foi definido levando-se em consideração o tamanho e a complexidade das unidades, o número de pesquisadores e as vagas disponíveis para os mesmos. Os embarques duraram de quatro a sete dias, período prolongado apenas nos três primeiros embarques (fase inicial de desenvolvimento da MDR) e quando havia um pesquisador novato na equipe.

Para cada unidade, a aplicação da Metodologia de Diagnóstico Rápido (MDR) foi realizada em três macroetapas distintas. Na primeira, de nivelamento das informações, alguns documentos eram solicitados à equipe de SMS. Essas informações auxiliavam na preparação para o embarque, pois permitiam que os pesquisadores formulassem e sanassem previamente algumas dúvidas sobre a operação cotidiana das plataformas e suas particularidades (porte, $P O B$, tempo de operação, tipos de processos, equipamentos especiais, etc.). Essa tipificação e comparação entre as características das unidades visitadas proporcionavam a definição prévia de alguns focos de observação a bordo.

Após a preparação prévia, era possível realizar a segunda macroetapa, de embarques para a coleta de dados a bordo. Logo no início do embarque, havia uma apresentação preliminar sobre o trabalho que seria desenvolvido em campo para o gerente da plataforma, as demais lideranças offshore (coordenadores e supervisores das diferentes equipes) e os técnicos de segurança. Após a reunião de apresentação, eram realizadas entrevistas (primeiro com os coordenadores e supervisores, depois com os trabalhadores) e visitas guiadas, além de acompanhamento de atividades de trabalho das equipes a bordo. Em função do tempo de permanência dos ergonomistas nas plataformas, eram priorizados os acompanhamentos das situações identificadas pelas equipes de cada unidade como as mais críticas acontecendo durante esse período.

Para facilitar as observações em campo, foi elaborado um roteiro com informações relativas ao trabalho de cada equipe, a serem levantadas a bordo pelos pesquisadores. Essas diretrizes não foram estruturadas como um checklist, mas como um roteiro sistemático que servia de ferramenta auxiliar, para que os pesquisadores se recordassem dos principais aspectos que deveriam observar, já que não poderiam estar muito tempo a bordo e seria difícil o retorno posterior à unidade. Essa ferramenta teve como objetivo acumular a experiência coletiva da equipe desenvolvida ao longo dos diferentes embarques, sendo utilizada como ajuda à memória e suporte aos pesquisadores menos experientes.

Em geral, o roteiro buscou retratar o funcionamento geral da empresa, a composição de cada equipe, as principais Situações de Ação Característica ${ }^{10}$ (SACs) e as dificuldades que os trabalhadores enfrentam para realizar suas atividades, além das condições dos equipamentos e dispositivos técnicos com que lidam, verificando o grau e o estado dos automatismos e as condições de acessos. Por outro lado, contemplou também a descrição das soluções colocadas em prática pelos

\footnotetext{
9 As MDRs em ergonomia podem ser necessárias em várias circunstâncias: equipe técnica reduzida, em quantidade ou em qualificação técnica especializada; grande quantidade de postos de trabalho a serem analisados, como acontece com demandas de grandes corporações que devem atender às exigências legais; restrição de tempo para realizar as análises, como ocorre nas intervenções em projeto; exigências de termos de ajustamentos de conduta; análise de acidentes, entre outras. No caso das plataformas offshore, a principal restrição é a disponibilidade de vagas para o embarque da equipe de ergonomia, restrição que também, veremos mais tarde, é um dos determinantes principais a considerar na análise da história das unidades.

10 As SACs sintetizam os determinantes do trabalho futuro, que existirão, independentemente das soluções técnicas escolhidas durante os projetos. Trata-se de situações que os operadores deverão gerir, no futuro, seja no contexto de um funcionamento normal, seja para o suporteao funcionamento (estoque, limpeza, entre outros), seja no contexto de incidentes. "A análise de situações de referência permite identificar situações [de ação] características [SACs] suscetíveis de surgirem na instalação futura. [...] O recenseamento de [SACs] será utilizado em todas as fases [do processo de concepção].” (DANIELLOU, 2002, p. 31-32).
} 
trabalhadores, que asseguram o bom funcionamento da unidade. Dessa maneira, os pesquisadores deveriam se interessar não só pelos problemas, mas também pelas boas soluções desenvolvidas em cada plataforma (algumas criadas por iniciativas dos próprios trabalhadores), para compartilhar essas informações com as demais unidades.

A terceira e última macroetapa, de análise e proposição dos planos de ação, era desencadeada a partir dos resultados obtidos com os embarques, cujas análises e recomendações compunham os relatórios ergonômicos, entregues à gerência das plataformas em terra, que os repassavam à gerência offshore.

Para finalizar a última macroetapa, foi realizado, com as plataformas do primeiro ciclo, um workshop para a apresentação dos resultados e melhores práticas, para o qual foram convidadas as principais lideranças em terra de cada plataforma. O propósito desse encontro foi duplo: promover a integração entre gerentes das diversas plataformas, que passavam por situações semelhantes, e divulgar as boas práticas observadas a bordo de cada uma delas.

A partir desta abordagem, a demanda inicial da área de SMS (Segurança, Meio ambiente e Saúde) da empresa de atender aos requisitos da legislação, em particular da Norma Regulamentadora NR-1 $7^{11}$ (BRASIL, 2007), que preconiza a realização da AET nas organizações, foi redefinida. Seria preciso reverter o círculo vicioso de acúmulo de pendências das plataformas, para melhorar as condições de trabalho e vida a bordo.

Por isso, para cada unidade, foram retraçados os processos históricos (encadeamento lógico-temporal) que geraram a situação vigente. $\mathrm{O}$ delineamento das suas origens, por meio da explicitação e da análise de determinados eventos marcantes, permitiu obter pistas sobre como reverter este círculo vicioso ou, ao menos, reduzir seus impactos negativos para os trabalhadores e para a operação das plataformas.

\section{O funcionamento real das plataformas: entre prescrição e degradação}

Todo trabalho está intimamente relacionado ao tipo de estrutura física e organizacional de uma empresa. A produção offshore não é diferente. Reconhecer a complexidade específica das plataformas é condição prévia para qualquer intervenção, pois cada uma dessas unidades marítimas se estrutura internamente e organiza suas atividades no dia a dia de forma singular. Essas singularidades determinam e são determinadas pela história de cada plataforma, cujos traços significativos são definidos desde a sua concepção, ou mesmo antes, caso se trate da conversão de uma antiga unidade de exploração ou de um navio.

A força de trabalho a bordo, denominada POB (People On Board - Pessoas a Bordo), realiza suas atividades em turnos de revezamento de 12 horas. As principais atividades são realizadas pelas equipes de produção; embarcação, que inclui movimentação de cargas, lastro (para $\mathrm{FPSOs}^{12}$ e unidades semissubmersíveis - SS) e cabotagem; manutenção principal, que abrange instrumentação, elétrica, mecânica e automação; manutenção complementar, que realiza tarefas de pintura, serviços de caldeiraria, limpeza industrial e montagem de andaimes. Há ainda hotelaria e atividades de apoio, que auxiliam nas instalações do casario, como cozinha, refeitório, paióis, enfermaria, lavanderia, recepção, sala de rádio, sala de telecomunicações, camarotes e áreas de lazer.

O trabalho offshore apresenta características marcantes, tais como: a periculosidade, reconhecida legalmente pela NR-16 $6^{13}$; a complexidade, diretamente relacionada à imprevisibilidade do sistema de produção e ao fato de os resultados de seus processos não serem imediatamente perceptíveis; o caráter contínuo desses processos e a atividade coletiva, ou seja, a necessidade de haver ações simultâneas e coordenadas de diversas pessoas, atualmente, em tempo real, envolvendo equipes onshore e offshore. Todas essas particularidades são potencializadas pelo confinamento em alto mar, que, em casos extremos, funciona como agravante dos riscos inerentes às atividades realizadas (PORTO; FREITAS, 1997; FIGUEIREDO, 1998; FERREIRA, 2002).

Costuma-se pensar que os trabalhadores não se dão conta dos riscos intrínsecos às suas atividades, por estarem habituados à rotina em alto mar. Contudo, essa visão é insustentável, sobretudo diante do aumento da fiscalização das condições de trabalho, que abrangem segurança, saúde e meio ambiente, tão em voga atualmente. Precisamente, por conviverem em permanência com o perigo, essas condições os obrigam, por exemplo, ao mapeamento preliminar dos riscos durante o processo de Permissões de Trabalho (PTs), que ocorre antes da execução de qualquer intervenção

\footnotetext{
${ }^{11}$ Conforme disposto na Lei no 6.514/77 - Portaria no 3.751/90 (BRASIL, 1990), que estabelece a obrigatoriedade de as empresas realizarem a Análise Ergonômica do Trabalho e deterem relatórios técnicos ergonômicos comprobatórios.

12 Floating, Production, Storage and Offloading-Navio utilizado como unidade flutuante de armazenamento de petróleo e/ou gás natural, e transferência da produção para navios aliviadores.

13 O item 16.1 da NR-16 de 07/01/2015 enuncia que “[...] são consideradas atividades e operações perigosas as constantes dos Anexos números 1 e 2 desta Norma Regulamentadora-NR” (BRASIL, 2015a, p. 1).
} 
de manutenção, ampliando a percepção de riscos e vulnerabilidades potenciais da planta.

As condições próprias ao trabalho nas indústrias de alto risco criam, assim, "[...] um clima de fundo de preocupação e de cuidados, que permeia tudo o que se faz no trabalho, [...] de constante atenção e tensão" (FERREIRA, 2002, p. 66). Essa atenção permanente joga a favor da segurança, sugerindo-se, aqui, a presença de processos de regulação complexos que não se reduzem à confiabilidade técnica e que são possíveis graças aos comportamentos de iniciativa dos trabalhadores (DANIELLOU; SIMARD; BOISSIÈRES, 2013).

Os sistemas produtivos, na prática, não são apenas tecnológicos, mas, também, sociais. Desse modo, os acidentes resultam de uma combinação de falhas tecnológicas, humanas, gerenciais, organizacionais e de inadequações dos projetos, que se refletem nas condições de trabalho (PERROW, 1984; WYNNE, 1987; WISNER, 1994). Especialmente após a ocorrência de grandes acidentes industriais, como em Three Mile Island (1979), da fábrica de pesticidas em Bhopal (1984) e de Chernobyl (1986), evidenciou-se que é preciso considerar os fatores humanos na confiabilidade dos sistemas organizacionais, uma vez que o estudo aprofundado dessas catástrofes permite compreender a situação real dos trabalhadores nas situações complexas e perigosas (LEPLAT; TERSSAC, 1990; WISNER, 1994; LLORY; MONTMAYEUL, 2014).

O modo de funcionamento das plataformas offshore, em operação há 20 anos ou mais, é próximo ao que se caracterizou como Modo Degradado de Funcionamento (MDF) (WISNER, 1989; KERBAL, 1990; DUARTE, 1994). O MDF foi inicialmente explicado como consequência de processos incompletos de transferência de tecnologia, sendo caracterizado por incidentes constantes, que requerem compensações dos trabalhadores, visando a manter a produção e controlar, tanto quanto possível, os riscos de acidentes. Sagar (1989, p. 33-34) ${ }^{14}$ afirma que as atividades compensatórias dos trabalhadores representam sua "[...] luta contínua contra as anormalidades da produção, através de ajustes e astúcias utilizadas para combater a degradação”. Existe, assim, um equilíbrio incerto entre a degradação e as competências dos trabalhadores, cuja negatividade ou positividade, no que diz respeito às consequências em termos de segurança, resta ainda por estabelecer.
Desde que se evidenciou a diferença incontornável entre o prescrito e o real, diferença extensível ao modo nominal de funcionamento e ao funcionamento real, certa "degradação" das instalações é, pode-se dizer, seu modo normal de funcionamento. Como e onde, então, estabelecer os limites entre a obsolescência normal e uma degradação inaceitável, que coloca em risco a segurança das instalações e das pessoas? Como explicar que, mesmo em condições adversas, essas plataformas apresentem menos acidentes do que seria esperado para uma indústria de alto risco?

A comparação da condição atual aos padrões e normas pré-definidos é o critério adotado pelas certificadoras e instituições fiscalizadoras. Isto equivale a submeter o real ao crivo da prescrição, salvo as tolerâncias admitidas nas próprias normas, eleitas como valor absoluto. Nesse sentido, a análise da atividade em situações reais pode oferecer respostas e critérios mais refinados e contextualizados, mais próximos às condições reais de produção, sem que a segurança seja relegada a um segundo plano. Este, porém, nada mais é que o credo geral da Análise Ergonômica do Trabalho (AET), que deve provar, em cada caso, como reconciliar produção e segurança, e, no caso em pauta, como diferenciar variabilidade normal de modo degradado e inventividade dos trabalhadores (hoje, dita proatividade) de "gambiarras" ${ }^{15}$ arriscadas.

No caso das plataformas estudadas, a origem dos problemas de conservação está relacionada a diversos fatores, como o envelhecimento das instalações; a defasagem decorrente da evolução das normas e recomendações de segurança ao longo do ciclo de vida; as demandas por intervenções de manutenção superiores à capacidade de execução com os recursos disponíveis (sobretudo devido à restrição de $P O B$ ), e a estratégia de continuidade e aumento da produção sem paradas prolongadas para a manutenção em estaleiros etc. (ROCHA, 2014).

O modo de funcionamento atual pode, assim, ter origem no envelhecimento normal (obsolescência técnica) das instalações que, em muitos casos, têm seu tempo de operação estendido para além do prazo da viabilidade econômica projetada. Com o mercado favorável, as plataformas mantêm-se rentáveis, mesmo com custos operacionais elevados, o que motiva estender sua operação para além dos prazos

\footnotetext{
14 Tradução livre dos autores para: “C'est une lutte continuelle contre l'effondrement de la production par des ajustements et des astuces utilisés pour compenser et combattre la dégradation".

15 Atualmente, nas grandes empresas, as invenções dos trabalhadores para assegurar a continuidade da produção são denominadas, eufemisticamente, de "soluções técnicas", como se a proscrição de se falar em "gambiarras" mudasse a natureza desses "jeitinhos" ou "improvisações", enquanto soluções informais e provisórias baseadas na experiência. Por isso, cabe diferenciá-los das soluções e/ou dispositivos técnicos confeccionados pelos próprios trabalhadores, que viabilizam o trabalho seguro e economicamente viável, ainda que não tenham sido desenvolvidos segundo os cânones da engenharia. A generalização do termo pejorativo de "gambiarra" a todas as invenções dos operadores institui uma contraposição que nega qualquer conteúdo técnico às soluções criadas pelos trabalhadores e reforça o mito de que somente os engenheiros projetam seguindo rigorosamente o método científico.
} 
previstos para retorno do investimento. Mesmo que essas decisões sejam tecnicamente fundadas, cria-se uma defasagem entre a realidade atual das instalações e as exigências legais, que mudam com a evolução das normas e recomendações de projeto ${ }^{16}$ dessas unidades.

Além disso, as origens do modo de funcionamento atual das plataformas podem retroceder a decisões nas etapas iniciais de projeto e adaptações de sistemas e equipamentos (como a conversão de navios em FPSOs), que requerem mais manutenção para que se mantenham operacionais, e na antecipação do início de produção, realizando start up prematuros, com pendências que poderiam ser eliminadas em estaleiro. Nessas circunstâncias, acaba-se criando um passivo de demandas por intervenções de manutenção offshore (tecnicamente denominado de backlog), que requerem mais recursos e tempo, quando realizadas a bordo, e que é superior à capacidade dos recursos disponíveis, sobretudo devido às restrições de $P O B$, que aparece, assim, como principal gargalo para explicar a lógica de priorização das demandas (ROCHA, 2014).

De modo geral, independentemente de sua gênese, o MDF manifesta-se em sintomas que já são bem conhecidos pelos trabalhadores e também descritos na literatura. As principais formas de perceber a degradação são quando os sistemas de instrumentação automática ficam recorrentemente fora do ar, sensores deixam de funcionar e o maquinário é utilizado em condições distintas das definidas pelos fabricantes, os quais, em alguns casos, são estrangeiros, o que implica na inadequação do uso e na manutenção impossibilitada ou negligenciada. Esses sintomas manifestam-se também quando os recursos humanos são insuficientes ou com baixa capacitação e experiência para operar os sistemas, e há baixa qualidade dos produtos, acidentes frequentes e patologias diversas (DUARTE, 1994; GOLDENSTEIN, 1997; PENTEADO et al., 1998). Esses sinais, quando bem analisados, revelam uma rede complexa de inter-relações e compensações recíprocas. A avaliação dos efetivos, por exemplo, considera também as atividades cognitivas e as estratégias de ação que permitem controlar as variabilidades e dificuldades no dia a dia da operação (DUARTE, 1994). Essa relação é também considerada nos projetos e adaptações dos postos e das condições de trabalho, especialmente nas unidades mais antigas, cuja degradação é mais frequente (DUARTE; VIDAL, 2000).
No caso das plataformas, devido à forte restrição de espaço, os sinais de degradação manifestam-se também em outros sinais. Na mesma medida em que aumenta o quantitativo de pessoas a bordo para a execução das ações de manutenção, também aumenta o embarque de materiais, os quais, em algumas plataformas, acabam sendo alocados para além das áreas de movimentação de cargas, como as quadras de esportes. Esse fato contribui para a diminuição da qualidade de vida a bordo, com impacto negativo no índice de satisfação dos empregados; mas, ao mesmo tempo, se presta a regular as necessidades de embarque dos materiais que servirão à melhoria das próprias instalações.

Em algumas plataformas, mesmo que provisoriamente, os espaços de convivência e lazer foram transformados em camarotes, para atender ao Anexo II da NR-30 ${ }^{17}$, enquanto não são realizados planos diretores de obras civis nos casarios. Em outras unidades, há a utilização de contêineres como camarotes (Módulos Temporários de Acomodações - MTAs), que também servem como escritórios, com postos de trabalho administrativos adaptados em espaços exíguos. O impacto sobre a qualidade de vida é, nesses casos, mesmo que temporariamente, imediatamente perceptível, pois, na vida offshore, o "trabalho" e a "casa" são dimensões inseparáveis. Por isso, a plataforma precisa oferecer condições de conforto e habitabilidade que tornem o período de isolamento em alto mar menos desgastante, além de resgatar, dentro das restrições existentes, algumas dimensões da vida em terra, como opções de lazer e comunicação com a família (COSTA, 2014).

Esses sinais, relacionados à operação ou à vida a bordo, ainda que impactantes à primeira vista, talvez mesmo por serem imediatamente visíveis, não podem levar a conclusões diretas sobre a gravidade ou o grau da degradação. Por isso, preferimos falar em termos de modo de funcionamento atual. Nesse sentido, o conceito de resiliência oferece um ponto de partida para se recolocar a questão da degradação, ao relativizar a condição atual de um sistema, cujo funcionamento é analisado em termos relacionais. Como definido por autores dessa abordagem (HOLLNAGEL; WOODS, 2006; WEICK; SUTCLIFFE, 2007), as Organizações de Alta Confiabilidade $\left(\mathrm{OAC}^{18}\right)$ praticam a segurança como uma capacidade intrínseca, o que as torna resilientes, ou seja, capazes de acomodar degradações

\footnotetext{
${ }^{16}$ Muitas recomendações hoje existentes foram publicadas em normas e/ou atualizadas posteriormente à construção dessas instalações, como, por exemplo, o Anexo II da NR-30 (BRASIL, 2015b), para o caso de plataformas e instalações de apoio, que trata de aspectos relacionados à segurança e saúde no trabalho aquaviário, publicado em 2010 e atualizado em 2011; a NR-34 (BRASIL, 2014a), relativa às condições e ao meio ambiente de trabalho na indústria da construção e reparação naval, de janeiro de 2011, atualizada em 2014; e a NR-35 (BRASIL, 2014b), relativa ao trabalho em altura, publicada em 2012 e atualizada em 2014.

17 O item 10.5.1.2 do Anexo II, da NR-30 de 20/01/2011 enuncia que "[...] o camarote não pode acomodar mais do que quatro pessoas e a área disponível não pode ser inferior a 3,6 $\mathrm{m}^{2}$ por pessoa" (BRASIL, 2015b, p. 11).

${ }^{18}$ Em inglês, High-Reliability Organizations (HRO), termo cunhado por Gene I. Rochlin, Todd R. La Porte e Karlene H. Roberts (ROCHLIN; LA PORTE; ROBERTS, 1998).
} 
parciais de seu estado, sem perda significativa de seu desempenho em termos de produção e segurança.

Entretanto, é preciso refletir sobre as condições nas quais é possível ser resiliente. Uma das dificuldades para a melhoria dessas condições é o adequado reconhecimento das "anormalidades normais", ou seja, quando os funcionamentos anormais passam a ser vistos como normais e a noção de integridade e manutenção passam a ser violadas no dia a dia, processo denominado por Vaughan $(1997,2004)$ de "normalização do desvio". Essa questão caracteriza um problema de gestão dos riscos, cuja minimização de sua importância e de seus impactos tende a gerar consequências cada vez mais graves, como os acidentes com vítimas registrados nas últimas décadas (PORTO; FREITAS, 1997; WYNNE, 1988 apud FIGUEIREDO, 1998).

Não é fácil, contudo, tirar conclusões ou fazer ilações entre esses acidentes e o funcionamento de plataformas offshore, sendo necessário estabelecer gradações entre um modo degradado de funcionamento típico, que levou a acidentes graves (como no caso de Bhopal), e deteriorações que não afetam a confiabilidade operacional. Todavia, reconhecidos os sintomas (alguns facilmente perceptíveis, como corrosão de pisos e guarda-corpos, vedações de vazamentos em tubulações), não se pode concluir que se trata de um MDF.

Com a ação do tempo nas plataformas que funcionam além da sua vida econômica projetada para 20 a 25 anos, torna-se necessário implementar programas de integridade e modernização das instalações, ocasião oportuna para a realização de estudos ergonômicos integrados às transformações dessas unidades, contribuindo tanto para melhorar a qualidade de vida quanto para manter a confiabilidade operacional.

\section{A ação ergonômica no tempo e no espaço: a metodologia padrão e os diagnósticos rápidos em ergonomia}

O trabalho está no cerne da relação entre o homem e a organização. As tarefas são as diretrizes de trabalho pré-fixadas - prescritas - e indispensáveis aos operadores, pois possibilitam a execução de suas atividades e o alcance, nas condições reais, dos resultados pretendidos. Porém, como sempre existe uma distância entre o prescrito e o real, entre "o que é pedido" e "o que é feito", é necessário descrever as estratégias usadas pelos operadores para a execução do que é demandado, entre as quais adaptações e improvisações que, muitas vezes, são vistas de forma negativa. De modo geral, a ergonomia mostra que os usuários adaptam os artefatos durante o uso, o que só pode ser percebido por meio de análises detalhadas no campo, que revelam o que escapa às descrições genéricas fornecidas pelas prescrições. A partir das observações, dos acompanhamentos das atividades e das verbalizações em autoconfrontação, podem-se aprofundar os conhecimentos sobre a organização real do trabalho (GUÉRIN et al., 1997; DANIELLOU, 2002; HUBAULT, 2004; DANIELLOU; BÉGUIN, 2007).

A subestimação da realidade do trabalho pode conduzir à existência de elevado número de equipamentos abandonados, subutilizados ou em condição degradada, e à alta frequência de interrupções não planejadas, em detrimento de manutenções preventivas. Além disso, pode conduzir ao enfraquecimento das relações de trabalho, marcadas pela existência de uma organização do trabalho anacrônica (KERBAL, 1990). O objetivo da ida ao campo é compreender as demandas de transformação do ponto de vista do usuário, com base na sua experiência em situações típicas de trabalho, gerando, a partir daí, processos de mudanças e de inovação (BÉGUIN, 2008).

Nesse aspecto, as análises ergonômicas, construídas a partir do acompanhamento das atividades realizadas pelos trabalhadores nas plataformas, contribuem para o reconhecimento das condições existentes e também para que sejam evidenciadas as estratégias utilizadas diante das dificuldades encontradas, bem como as oportunidades gerais de melhoria.

Contudo, devido às restrições de $P O B$, as análises ergonômicas a bordo são dificultadas pelas limitações quanto ao número de dias e à quantidade de embarques, ao tamanho e à complexidade da plataforma, ao número de pesquisadores e à logística de transporte de pessoas de terra para as unidades. Sem dúvida, é preciso estar junto aos trabalhadores para compreender, resgatando sua experiência em ação, as dificuldades que enfrentam. Mas, durante quanto tempo? Como a duração das observações de campo influencia a qualidade do conhecimento que se produz sobre a atividade de trabalho e suas condições? É possível economizar tempo (e recursos especializados) sem perder a profundidade das descrições das situações de trabalho, condição para formular recomendações de transformação efetivas? Essas são as questões com as quais nos defrontamos diante da demanda de realizar avaliações ergonômicas em diferentes plataformas operando nas costas brasileiras.

Com sua metodologia padrão de Análise Ergonômica do Trabalho (AET) e intervenção (sistematizada inicialmente em GUÉRIN et al., 1997; em uma versão mais atual, conforme FALZON, 2007), a ergonomia, apoiada na análise sistemática da atividade em situações reais, já deu provas suficientes de sua capacidade de fazer diagnósticos aprofundados sobre as relações 
trabalho-saúde-desempenho e, assim, contribuir para promover transformações significativas das situações de trabalho, sobretudo quando atua na fase de projeto (ergonomia de concepção).

No entanto, as análises das atividades desenvolvidas podem requerer vários dias, sendo tanto mais longas quanto maior a diversidade de atividades e situações de trabalho. A duração das análises ergonômicas depende, assim, das características da própria atividade que se quer conhecer, ou seja, a metodologia de análise se ajusta às peculiaridades espaciais e temporais das situações reais: o observador, diretamente ou por meio de suas técnicas de observação, deve acompanhar a atividade se desenrolando no espaço e no tempo, descrevendo lugares e momentos significativos ${ }^{19}$. Estando sujeitas às condições não controladas das situações naturais de trabalho, as análises ergonômicas acomodam-se ao tempo e ao lugar da atividade. No entanto, a duração relativamente longa das análises ergonômicas tem sido objeto de críticas, revelando-se como uma limitação que impede sua utilização em grande escala, quando se colocam demandas que exigem, por exemplo, avaliar as condições de trabalho em um ramo de produção considerado prioritário.

Por outro lado, para atender às exigências legais, algumas empresas, independentemente do seu porte, solicitam análises ergonômicas de todos os postos de trabalho, que podem chegar, no caso de grandes corporações, a alguns milhares de trabalhadores. A duração de uma intervenção, ou da etapa de análise, se torna ainda mais crítica no presente caso da fiscalização das plataformas brasileiras, que acumularam demandas a serem atendidas em um curto período de tempo, devido às exigências impostas pelos órgãos de fiscalização.

Assim, as análises ergonômicas deveriam ser realizadas em poucos dias de embarque, principal restrição das plataformas, mas produzindo relatórios suficientemente fundamentados para orientar a elaboração de programas de ação para cada unidade. Responder a essas demandas, nas condições em que elas se apresentaram, exigiu repensar as condições e possibilidades de diagnósticos rápidos em ergonomia. Se as intervenções ergonômicas devem produzir um conhecimento da atividade de trabalho a bordo, para apoiar as transformações futuras, como análises ergonômicas realizadas a partir de dados obtidos em poucos dias de observação podem gerar esse conhecimento aprofundado? Como a análise das atividades realizadas pelos trabalhadores e os relatórios decorrentes delas podem efetivamente contribuir para a transformação das condições de trabalho a bordo? Como, superar o MDF - condição supostamente revelada pelas fiscalizações como modo atual de operação das unidades -, ou seja, produzir mudanças efetivas e não apenas fazer de conta para satisfazer determinações legais?

Métodos de avaliação estruturados, como checklists, são bastante difundidos e utilizados devido a simplicidade e rapidez de aplicação. Os Pontos de Verificação Ergonômica (PVE) (INTERNATIONAL LABOUR OFFICE; INTERNATIONAL ERGONOMICS ASSOCIATION, 2010), desenvolvidos para uso em pequenas empresas, e o OWAS (Ovako Working Posture Analysis System) ${ }^{20}$ (CARDOSO JUNIOR, 2006), ferramenta de análise postural, são métodos que podem ser combinados à AET. Além destes, há outros métodos mais específicos, para mensurações de carga e potencial de ocorrência de lesões, sem analisar o contexto (a abrangência) em que são desenvolvidas as atividades, como o RULA (Rapid Upper Lim Assessment) (MCATAMNEY; CORLETT, 1993) e o do NIOSH (National Institute for Ocupational Safety and Health) (AGAHNEJAD, 2011). Não trataremos, aqui, desses métodos, que estão mais distantes da AET, embora a necessidade de rapidez também se coloque, sem, contudo, passar pela simplificação ou adequação a finalidades específicas, nas quais se perdem as relações entre atividade e contexto.

No campo da ergonomia da atividade, os principais relatos sobre os diagnósticos curtos (diagnostic court) são sobre as experiências da ANACT francesa (Agence Nationale pour l'Amélioration des Conditions de Travail - Agência Nacional de Melhoria das Condições de Trabalho) e de suas Ações Regionais (ARACTs - Actions Régionales pour l'Amélioration des Conditions de Travail), que, entre os anos de 1990 e 1993, realizaram de forma gratuita, como uma ajuda ao governo francês, mais de 1.400 diagnósticos em pequenas e médias empresas. À época, uma equipe, em apenas cinco dias, focava sua análise nas situações de trabalho e suas consequências, a fim de revelar os principais problemas enfrentados pela empresa, procurando abrir um espaço para debater e negociar melhorias das condições de trabalho. O objetivo dos diagnósticos era colocar essas empresas em movimento, em pequenos passos, ao promover o entendimento das condições de trabalho e os desafios de eventuais modificações da

\footnotetext{
${ }^{19}$ Evidentemente, nenhuma descrição pode se pretender exaustiva, descrevendo todos os indexadores espaçotemporais da atividade, menos ainda dar conta da experiência vivida do trabalhador observado. O "recorte" orientado pela demanda, ou seja, pelo problema que se quer resolver, permite delimitar o campo da análise, de forma a atender a esses critérios de pertinência situacional e experiencial sem empobrecer as descrições da atividade.

${ }^{20}$ Foi desenvolvido em meados dos anos 1970 pelo grupo siderúrgico Finlandês OVAKO OY, em parceria com o Instituto Finlandês de Saúde Ocupacional (CARDOSO JUNIOR, 2006).
} 
organização e do conteúdo do trabalho, nos domínios das condições e da duração do trabalho, do emprego e da formação (DELTOR; GUÉRIN, 1994; VINCENTI, 1994; SILVA, 2007).

Vincenti (1994), por meio da análise aprofundada de 21 casos, salientou que o comportamento estratégico da equipe é fundamental para realizar o percurso de analisar a demanda, elaborar o diagnóstico e colocar em movimento a empresa. Isto é, a estratégia de ação deve ser construída a partir da demanda central, o que é determinante para a identificação do que se pode alcançar com o diagnóstico rápido. Contudo, o principal risco dessa construção é que o diagnóstico deve ser aplicado como uma intervenção ergonômica, no que tange ao seu planejamento, à estruturação e à forma de condução, mas não pretende ser propriamente uma intervenção em miniatura, na qual os métodos habituais duram o tempo que for necessário à ação, especialmente à observação. Desse modo, configura um grande desafio reconhecer a fragilidade da compreensão do problema e a necessidade de seu aprofundamento posterior (DELTOR; GUÉRIN, 1994; SILVA, 2007; COSTA, 2014).

A principal vantagem de aplicação de MDRs é a devolução dos resultados aos atores sociais mais rapidamente. Todavia, há dificuldade em apreender objetivamente os efeitos do diagnóstico rápido por duas razões. Primeiro, pelo prazo que decorre entre as auditorias e a implementação das recomendações, pois nem sempre os resultados são imediatos e podem ser percebidos em curto prazo. Além disso, dificilmente se consegue retornar à empresa para fazer uma nova avaliação, com base na anterior (BOUTTERIN, 1994; VINCENTI, 1994). Reconhecidas essas limitações, as MDRs podem ser, como veremos, um instrumento eficaz para a construção de ações estratégicas em ergonomia.

\section{Os resultados da MDR desenvolvida para plataformas de petróleo}

Essa experiência de desenvolvimento de uma MDR, ainda em processo de aperfeiçoamento, foi suficiente para perceber sua dupla eficácia: permite evidenciar alguns princípios gerais, que ajudam a identificar de forma sistemática situações específicas que devem ser melhoradas, mas também permite compreender processos mais amplos que levaram ao acúmulo de pendências e condições ergonomicamente inadequadas. Ter uma avaliação global, que vá além da identificação de situações críticas específicas, é importante para explicar como e por que essas condições foram geradas e, em consequência, que estratégia adotar para sua solução de forma mais definitiva.

Com efeito, boa parte das situações identificadas - e apresentadas em relatórios específicos de cada plataforma - foi revelada por técnicas que configuram uma metodologia rápida de avaliação ergonômica, em especial visitas guiadas e entrevistas com trabalhadores experientes e que ocupam posições-chave na equipe embarcada. Mesmo observações de curta duração (de três a cinco dias a bordo), utilizando esta abordagem, permitiram evidenciar uma grande quantidade de inadequações ergonômicas, graças à experiência acumulada pelas diversas equipes da plataforma - manutenção, operação, embarcação, facilidades, terceirizados, entre outras -, mas também pela experiência que vai sendo acumulada pela equipe de ergonomistas ${ }^{21}$.

Isso significa que a maior parte dos problemas já é conhecida, seja pela equipe embarcada, seja porque os ergonomistas já os conheciam de outras plataformas. As visitas guiadas e as entrevistas complementaram os registros formais com uma série de problemas que não são registrados ou por não serem prioritários ou porque passaram a ser considerados "normais" (sobre a normalização de riscos, ver VAUGHAN, 1997).

O fato de a maior parte dos problemas já ser conhecida coloca questões de natureza mais geral, não mais sobre o diagnóstico específico, mas sim sobre o processo de acumulação de pendências ergonômicas, que configuram certo grau de degradação do sistema, que oscila entre dois extremos: de alterações mais anódinas a deteriorações que podem comprometer a confiabilidade do sistema. Essa ampla paleta, perceptível apenas quando a análise vai além da aparência imediata do estado das instalações, nos levou a reinterrogar o conceito de "modo degradado de funcionamento", de modo a considerar as gradações das deteriorações quanto ao potencial de risco.

\section{Revisitando o conceito de Modo Degradado de Funcionamento (MDF)}

Avaliações polarizadas entre funcionamento normal e funcionamento degradado obscurecem uma ampla gama de estados intermediários que, na realidade, constituem as formas de existências efetivas, desde que se reconheceu que nenhum equipamento opera em sua condição nominal, estando sempre abaixo ou acima dessa condição que serve apenas como

\footnotetext{
${ }^{21}$ A importância da experiência da equipe de ergonomistas para assegurar a eficácia da MDR nos foi assinalada por Jacques Duraffourg, em uma de suas visitas ao Brasil, comentando as experiências, nem sempre bem-sucedidas, da ANACT francesa; essa informação, valiosa, que não aparece nos textos relatando o método e os resultados das intervenções.
} 
prescrição inicial de projeto. Essas alterações em relação ao estado nominal de funcionamento podem afetar o desempenho do sistema também de forma positiva, embora sejam os aspectos negativos os mais enfatizados pelo conceito de MDF.

Necessário é considerar que o desempenho global é multicritério e um desempenho em termos de produção pode ser melhorado em detrimento da vida útil do equipamento, da qualidade ou da segurança. Isso torna mais complexa a avaliação do $\mathrm{MDF}$, por se tratarem de critérios heterogêneos, com valorações e tempos de manifestação diferentes (efeitos de curto ou longo prazo), e probabilidades de ocorrência bem discrepantes, que vão da certeza da produção imediata à possibilidade longínqua de uma falha.

Aqui, as reflexões de Canguilhem (2002) sobre o normal e o patológico são de grande valia para nos ajudar a compreender essas nuances da degradação e de sua valoração. A doença não é uma variação negativa da dimensão da saúde; ela é uma nova dimensão da vida, ou seja, uma realidade com a qual é preciso equilibrar-se e adaptar-se. Somente existe doença quando o indivíduo é incapaz de instituir outras normas de vida condizentes com sua condição atual. Quando, portanto, perde sua capacidade normativa. De modo análogo,

[...] se as indústrias forem pensadas como organismos vivos e dinâmicos, assim como o corpo humano, o Modo Degradado de Funcionamento, em certos casos, pode ser visto como um modo de operação com o qual é preciso conviver e cuja magnitude ainda resta a estabelecer. (COSTA, 2014, p. 36).

Se o normal não pode mais ser visto como um ideal, do qual estamos mais ou menos distanciados, como definir modos de funcionamento aceitáveis ou razoáveis? Por outro lado, isso também remete à necessidade de se compreender esses processos de degradação de modo mais amplo: se esses problemas são evidentes, já conhecidos e alguns formalmente registrados como demandas recorrentes de manutenção (que apenas alimentam o backlog, até serem "esquecidas"), por que não se consegue resolvê-los e reverter a tendência de aumento da degradação?

Como toda analogia, o modelo do organismo revela, aqui, seus limites. Se a vida segue de modo inexorável suas leis biológicas, indiferentes às normas sociais, os padrões de funcionamento aceitáveis das unidades de produção dependem, no essencial, de determinações sociais de custo, segurança, conforto, etc., que são objeto de debates entre os homens. Essas questões remetem, assim, a determinações sociais mais gerais, que permitem esclarecer os processos de gênese dos modos degradados, além de caracterização de estados determinados. É preciso reconstituir o filme, a narrativa que dá sentido à fotografia instantânea, como uma imagem técnica que pode ser interpretada de diversas formas (FLUSSER, 2011). Repetimos, em cada plataforma, a etnografia histórica que Vaughan (2004) fez no caso da Challenger, com bem menos profundidade, mas procurando resgatar eventos que marcaram sua trajetória.

Nesse sentido, essas avaliações iniciais resultantes da MDR permitiram elaborar alguns princípios explicativos mais gerais, que devem integrar uma metodologia de avaliação ergonômica de plataformas em operação, para além do levantamento de inadequações pontuais (COSTA, 2014, p. 159-160):

1. A história de cada plataforma, do projeto à operação atual, permite compreender como são definidas prioridades e por que existem pendências que ainda não puderam ser resolvidas;

2. Opções de projeto, como o aproveitamento de equipamentos e das instalações - de um antigo navio, no caso das FPSOs, ou a conversão de sondas de perfuração em unidades SS -, podem gerar problemas crônicos de manutenção com forte impacto no $P O B$, impedindo ou atrasando o atendimento a outras demandas menos prioritárias;

3. Uma plataforma (como qualquer outra instalação industrial) é uma entidade dinâmica, que não apenas envelhece como também apresenta melhorias que as equipes vão desenvolvendo com o passar dos anos. Assim, a metodologia deve recuperar tanto as situações inadequadas como as boas soluções;

4. A autonomia das equipes de cada plataforma, para estabelecer prioridades e um programa de manutenção que contemple todas as pendências, é limitada por uma série de interferências que fogem ao seu controle e que reduzem a disponibilidade de recursos, sobretudo em função do limite do $P O B$ :

a. Ações do PCM (Planejamento, Construção e Montagem), algumas das quais herdadas desde a fase de construção;

b. Opções de projeto que geram dificuldades operacionais e problemas crônicos;

c. Programas especiais, decididos por instâncias superiores, internas e externas (corporativo, organismos de fiscalização e certificação, entre outros), que alteram prioridades ou restringem recursos (inclusive $P O B$ ). Programas como o de integridade podem favorecer as melhorias, mas também podem gerar atrasos de outras ações necessárias; 
d. Dificuldade na coordenação entre funções diversas, onshore e offshore (suprimentos, logística, programação de embarque, liberação de PTs,), pode gerar atrasos para execução dos serviços de manutenção e integridade que visam à correção das inadequações;

Apresentamos a seguir um exemplo que nos levou a essas avaliações de natureza mais geral. Em uma das plataformas visitadas, foi feita a opção de manter, após a conversão do navio em FPSO, o sistema de geração de energia principal (formado por caldeira) e também o auxiliar (por gerador). Por volta de dois anos após o início da operação, a caldeira apresentou problemas operacionais e parou de funcionar; recorreu-se, então, ao gerador auxiliar original que, na época, também não funcionou. Para suprir a demanda de energia da plataforma, até que um novo sistema de geração fosse instalado, foi necessário embarcar outros geradores auxiliares.

A instalação deste novo sistema foi realizada offshore e durou cerca de seis anos, registrando picos de até 70 trabalhadores dedicados a essa atividade (cerca de $40 \%$ da capacidade da plataforma). De acordo com relatos, durante esse tempo, por falta de vagas suficientes para atender a todas as demandas da unidade, foi necessário priorizar algumas atividades em detrimento de outras e, portanto, várias demandas, como o tratamento mecânico e a pintura, foram suspensas. A consequência, então, foi o desvio de um contingente que deveria estar executando obras voltadas para a manutenção da integridade da plataforma, o que certamente contribuiu para gerar um passivo de manutenção, anos depois (ROCHA, 2014).

Essa análise histórica é, talvez, mais importante que a identificação de inadequações específicas, sobretudo porque a maioria delas já era conhecida. Ela esclarece o processo singular de acúmulo de pendências ergonômicas e permite implementar uma estratégia ao mesmo tempo global (por exemplo, o flotel ou Unidade de Manutenção e Segurança - $\mathrm{UMS}^{22}$ ) e específica para cada plataforma, de modo a aumentar a autonomia da equipe embarcada para gerenciar prioridades (COSTA, 2014).

Para observadores externos, os diagnósticos realizados nessas plataformas podem sugerir que elas estejam operando em condições de risco. Como acontece após cada acidente, eventuais pendências são reveladas na investigação, sendo aventadas possíveis relações com a cadeia de eventos que produziu o acidente. Na verdade, constatar certa degradação no sistema de produção é fácil e mesmo inevitável, tendo em vista que seu estado de funcionamento atual é sempre diferente do estado nominal; o difícil é estabelecer uma relação causal entre essas condições mais ou menos degradadas e o evento ocorrido. Além de pecarem por serem relatos retrospectivos, quanto à cadeia de eventos que levou ao acidente, por força do já acontecido, dos eventos mais evidentes, os profetas dos fatos acontecidos se limitam a constatar uma série de eventos sem analisar as relações de determinação que existem entre estes, como se a simples presença de um fato fosse razão suficiente para esse fato atuar como causa.

O conceito "modo degradado de funcionamento", devido à valoração negativa que acompanha o termo "degradação", pode ser interpretado como assumir riscos desnecessários, como se um sistema pudesse ser mantido sempre em um estado ideal. Assim como um trabalhador se cansa durante o trabalho, o modo degradado de uma instalação é o seu funcionamento normal, que não se define por um ponto estático ou ideal (e idealizado), mas sim por um processo em permanente transformação, que pode tanto se degradar como, em certos aspectos, melhorar.

Como o projeto continua no uso, a instalação em operação já não é a mesma idealizada no projeto pelo funcionamento nominal. O importante não é constatar alguma inadequação ergonômica, mas sim se o sistema consegue se recuperar adequadamente para operar sempre em estado de funcionamento seguro. Parte desses processos evolutivos depende da capacidade das equipes que conseguem, até certo ponto, compensar deficiências das instalações. Essa condição torna-se preocupante quando os processos de regulação sociotécnica entram em círculos viciosos entre demandas crescentes de manutenção e os consequentes aumentos da ocupação de recursos (homens-hora, materiais e $P O B$ ), mudanças de prioridades, aumento das demandas em espera e assim por diante, evoluindo em direção a uma degradação permanente e não controlada.

\section{Considerações finais: para que servem as MDRs?}

Metodologias de avaliação rápida em ergonomia ainda são pouco sistematizadas e as tentativas de utilização têm sido malsucedidas, por criarem padrões de observação demasiadamente fechados (como checklists) ou por pretenderem, com essa formalização, substituir a experiência de ergonomistas sêniores. A utilização de

\footnotetext{
22 As Unidades de Manutenção e Segurança são plataformas de serviço, que se conectam às unidades de produção, evitando a parada de produção e seu deslocamento até os estaleiros. Sua principal característica é disponibilizar alojamentos para as equipes que atuam nas revitalizações, funcionando como um navio-hotel (flotel) e ampliando o POB durante o dia. Em termos estratégicos, permite prolongar a viabilidade econômica projetada de plataformas de produção e manter a produção estável.
} 
roteiros mais abertos tem a vantagem de se fundamentar em avaliações anteriores e, ao mesmo tempo, se abrir às especificidades locais, enriquecendo-se também da experiência dos trabalhadores. Assim, abrevia-se o tempo de observação, sem perder em amplitude das condições observadas ou diminuir a importância das inadequações.

A análise de diversas instalações offshore, mesmo em curto espaço de tempo, permitiu fazer um levantamento sistemático das condições de trabalho e de vida a bordo, e gerar recomendações para elaborar programas de ergonomia, contribuindo, inclusive, para a confiabilidade operacional. A preparação prévia para os embarques, baseada na experiência acumulada da equipe de ergonomia, dos trabalhadores de terra e dos embarcados foi a condição necessária para a eficácia dessa metodologia de diagnóstico rápido em ergonomia.

A contribuição da AET, nesse caso, foi possível graças à identificação de um novo foco de análise: a história que gerou o modo de funcionamento atual. Sem produzir conhecimentos aprofundados sobre cada situação de trabalho ou inadequação ergonômica observada, as dezenas de casos repertoriados, analisados em conjunto, permitiram caracterizar a dinâmica que levou ao modo atual de degradação. Uma atuação localizada e breve forneceu elementos para desenvolver um modelo de análise que sintetiza três temporalidades: (1) a natureza crônica das inadequações (quase sempre bem conhecidas); que (2) se acumulam em um dado instante (ou sincronicamente), e que (3) se explicam por um processo diacrônico (ou propriamente histórico).

A história da plataforma foi, então, a chave para compreender seu estado atual de funcionamento, resultante da gestão de demandas de manutenção que aparecem ao longo de sua vida operacional, com priorizações condicionadas por características herdadas de decisões tomadas desde o projeto conceitual, passando por eventos marcantes nas etapas de fabricação e de exploração.

Essa metodologia não substitui a análise aprofundada da atividade, indispensável para suportar a construção de soluções detalhadas e implementar melhorias em relação ao funcionamento atual de uma unidade. Entretanto, se mostrou efetiva para alavancar a restauração de condições de funcionamento normal, ou seja, para criar uma tendência contrária aos processos de degradação e, sobretudo, contribuir para recolocar a operação e a manutenção da plataforma sob o controle das equipes embarcadas, alimentando o círculo virtuoso da confiabilidade operacional.

Algumas melhorias das condições de trabalho e ações de redução do funcionamento degradado das plataformas podem ser executadas de forma simples e, em princípio, rápida. Outras demandam uma implementação mais demorada, seja por necessidade de uma análise mais aprofundada da situação de trabalho e dos recursos físicos e humanos envolvidos, para que se construa uma solução, seja por envolver a mobilização de maiores recursos, tais como mudanças de tecnologia ou paradas/substituições de equipamentos.

Em função disso, nas análises realizadas, optou-se pela organização das recomendações em dois tipos: melhorias que podem ser implementadas em curto prazo e as que podem ser implementadas em médio/longo prazos. Entretanto, duas ações parecem ser vitais para garantir a execução das mudanças propostas:

- Integrá-las aos programas e ações institucionais de SMS, de modo que as melhorias não concorram com o dia a dia operacional, levando-se em consideração o planejamento e as possibilidades de realização de obras a bordo, além da urgência de aspectos que devem ser priorizados, principalmente quando estes estão relacionados à segurança da operação;

- Instituir comissões embarcadas, para cada unidade de produção, que acompanhem e auxiliem no andamento da implementação das recomendações ergonômicas, como forma de assegurar a realização dos programas de ação sob o controle das equipes offshore, por exemplo, executando parte do planejamento e da solicitação de materiais necessários para as revitalizações. Essas ações de apoio são consideradas essenciais pelo $P O B$, e devem ser formalizadas com recursos devidamente alocados, haja vista que o foco das equipes das unidades é mantê-las operacionais, o que já toma grande parte de seu tempo a bordo.

A abordagem desenvolvida buscou ainda recuperar parte da experiência acumulada pelas equipes embarcadas, sistematizadas nas histórias repertoriadas e nas iniciativas de melhoria empreendidas pelos próprios trabalhadores. Isso sugere que as soluções para os problemas desses sistemas técnicos podem estar dentro deles mesmos, com as equipes embarcadas, que conhecem o funcionamento real das unidades. Contudo, é preciso dar-lhes voz e oportunidade de compartilhar suas ideias, opiniões e competências, criando uma rede de iniciativas de melhoria. Esse é um dos caminhos que pode ser seguido para tentar reverter a situação atual e para tornar os trabalhadores sujeitos das ações de melhoria.

Para além de reagir a uma determinação legal ou às autuações, a MDR coloca em evidência a necessidade de se compreenderem as dimensões estratégicas pelas quais passa a reversão do processo de degradação, a fim de instaurar um processo contínuo de melhorias das condições de trabalho e de vida nas plataformas. Somente assim as avaliações ergonômicas deixarão 
de ser consideradas apenas como mais uma cobrança para as lideranças, em meio ao complexo dia a dia da gestão das unidades. Nesse sentido, é preciso pensar em novas estratégias de manutenção e de recuperação da confiabilidade dos sistemas e dispositivos técnicos, visando a reverter o círculo vicioso do acúmulo de pendências, que pode levar a um estado de degradação não controlável.

A efetividade dos métodos rápidos parece-nos, assim, não generalizável quanto ao seu desenho possível e quanto ao conteúdo que podem gerar, características estas que dependem do contexto da intervenção. O certo é que, em qualquer caso, como estudos sobre competências nos ensinam, só se pode ganhar tempo sem perder qualidade quando existe uma experiência acumulada a ser capitalizada em uma nova situação. Entretanto, essa passagem entre experiência e análise rápidas não é direta, nem evidente. Além dos desenhos específicos que dependem de cada demanda, é necessário considerar que ajustes são aceitáveis e possíveis para economizar tempo, sem perda de qualidade.

Uma condição necessária deve ser a distinção entre degradação normal e degradação anormal, que podem ser analisadas em termos de diferenciações entre relações de produção contingentes e relações de produção necessárias. No primeiro caso, trata-se de determinações histórico-sociais que, momentaneamente, obrigam a privilegiar a produção em relação à segurança, fazendo com que a confiabilidade dos sistemas de produção seja regulada em nível inferior ao que a experiência coletiva dos homens produtores poderia atingir. Nesse caso, se encaixam decisões que determinam start up prematuros, a fim de se atingirem metas de produção definidas segundo critérios exclusivamente econômicos. Por outro lado, nem toda adaptação advém de imposições econômicas, mas demonstram a inteligência dos trabalhadores para lidar com a realidade que escapa ao que sabemos e dominamos. Não se pode trabalhar sem assumir certos riscos. Essa negociação entre produção e segurança é permanente, insuperável e, portanto, necessária.

Finalmente, a MDR desenvolvida teve como objetivo não somente repertoriar inadequações de situações específicas, mas sim, a partir delas, compreender o processo que as gerou em tal proporção. Se a duração das observações sobre as quais se funda o diagnóstico é curta, o horizonte deve ser ampliado, começando por considerar decisões tomadas desde o projeto de base. Dessa forma, esse é o principal ganho dessa experiência: um processo crônico de degradação pode ser revertido a partir de diagnósticos rápidos, que possibilitem uma visão das singularidades de cada unidade de produção, narradas em uma história, que permita colocar a empresa em movimento para debater sobre as mudanças e ações estratégicas necessárias à inflexão de uma dada trajetória. Talvez, aqui, esteja uma das possibilidades de ampliar a prevenção de acidentes que seguem caminhos imprevisíveis, eliminando as falhas latentes e sua propagação catastrófica, que alguns, como Perrow (1984), consideram inevitáveis.

\section{Contribuições de autoria}

Os autores contribuíram igualmente no desenvolvimento do projeto de pesquisa e na elaboração deste artigo.

\section{Referências}

AGAHNEJAD, P. Análise ergonômica no posto de trabalho numa linha de produção utilizando método NIOSH: um estudo de caso no polo industrial de Manaus. 2011. 92 p. Dissertação (Mestrado em Engenharia Elétrica)-Universidade Federal do Pará, Pará, 2011. Disponível em: < http://www.itegam.org.br/ upload/pdf/dissert_payman.pdf $>$. Acesso em: 13 dez. 2013.

ANDERSON, M.; DENKL, M. The Heinrich accident triangle: too simplistic a model for HSE management in the 21st century? In: SPE INTERNATIONAL CONFERENCE ON HEALTH, SAFETY AND ENVIRONMENT IN OIL AND GAS EXPLORATION AND PRODUCTION, 2010, Rio de Janeiro. Proceedings... Dallas: SPE, 2010. http://dx.doi. org/10.2118/126661-MS.
BÉGUIN, P. Argumentos para uma abordagem dialógica da inovação. Laboreal, Portugal, v. 4, n. 2, p. 72-82, 2008.

BOUTTERIN, C. Les enseignements de l'évaluation du diagnostic court. In: BOUTERRIN, C.; DELTOR, S.; GUÉRIN, F. (Org.). Évaluation du diagnostic court: pour une évolution des pratiques et une plus grande efficacité de l'action. França: ANACT, 1994. p. 7-30. (Le Cahiers de L'ANACT, 1).

BRASIL. Ministério da Previdência Social. Lei $\mathrm{n}^{\mathrm{o}}$ 6.514 - Portaria MTPS no 3.751, de 23 de novembro de 1990. Altera o Capítulo V do Título II da Consolidação das Leis do Trabalho, relativo à segurança e medicina do trabalho e dá outras providências. Diário Oficial [da] República Federativa do Brasil, Brasília, DF, 26 
nov. 1990. Disponível em: <http://www.planalto. gov.br/ccivil_03/leis/l6514.htm>. Acesso em: $10 \mathrm{dez}$. 2013.

. Ministério do Trabalho e Emprego.

Portaria SIT n. ${ }^{\circ}$ 13, de 21 de junho de 2007. NR-

17: Ergonomia. Diário Oficial [da] República

Federativa do Brasil, Brasília, DF, 26 jun. 2007.

Disponível em: <http:/portal.mte.gov.br/data/files/ FF8080812BE914E6012BEFBAD7064803/nr_17.pdf $>$. Acesso em: 30 abr. 2015.

. Ministério do Trabalho e Emprego. Portaria MTE n. ${ }^{\circ}$ 592, de 28 de abril de 2014. NR-34: condições e meio ambiente de trabalho na indústria da construção e reparação naval. Diário Oficial [da] República Federativa do Brasil, Brasília, DF, 30 abr. 2014a. Disponível em: <http://portal.mte.gov.br/ data/files/8A7C816A468FE52F0146AA446DF42026/ NR-34\%20(Atualizada\%202014).pdf>. Acesso em: 21 maio 2015.

. Ministério do Trabalho e Emprego. Portaria MTE n. $^{\circ}$ 1.471, de 24 de setembro de 2014. NR-35: trabalho em altura. Diário Oficial [da] República Federativa do Brasil, Brasília, DF, 25 set. 2014b. Disponível em: < http://portal.mte.gov.br/data/files/ FF80808148EC2E5E014961BFB192220B/NR-35\%20 (Atualizada\%202014)\%202.1b\%20(prorroga).pdf > . Acesso em: 21 maio 2015.

. Ministério do Trabalho e Emprego. Portaria $\overline{\mathrm{MTE}}^{\mathrm{o}}$ 05, de 07 de janeiro de 2015. NR-16: atividades e operações perigosas. Diário Oficial [da] República Federativa do Brasil, Brasília, DF, 08 jan. 2015a. Disponível em: <http://portal.mte.gov.br/ data/files/8A7C816A4B277C09014B4A45540355EF/ NR-16\%20(atualizada\%202015).pdf > . Acesso em: 21 maio 2015.

. Ministério do Trabalho e Emprego. Portaria $\overline{\mathrm{SIT}^{\mathrm{O}}}$ 200, de 20 de janeiro de 2011. Anexo II: plataformas e instalações de apoio. Diário Oficial [da] República Federativa do Brasil, Brasília, DF, 02 jan. 2015b. Disponível em: < http://portal.mte.gov.br/ data/files/8A7C816A4AC03DE1014AE95913121041/ NR-30\%20(atualizada\%202015).pdf > . Acesso em: 21 maio 2015.

CANGUILHEM, G. O normal e o patológico. 7. ed. Rio de Janeiro: Forense Universitária, 2002.

CARDOSO JUNIOR, M. M. Avaliação ergonômica: revisão dos métodos para avaliação postural. Revista Produção Online, Florianópolis, v. 6, n. 3, p. 133-154, set./dez. 2006.

CHAMBRIARD, M. Comissão parlamentar mista de inquérito petrobras (CPMI - PETRO): requerimentos n. 539/2014 e 456/2014. Brasília, 2014. Disponível em: <http://www.petrobras.com.br/lumis/portal/file/ fileDownload.jsp?fileId=8A16DC644B42E4E1014BB7 D362AC36A0> . Acesso em: 21 maio 2015.
COSTA, P. G. F. Diagnóstico rápido em ergonomia: aplicação em plataformas offshore na Bacia de Campos. 2014. 221 p. Dissertação (Mestrado em Engenharia de Produção)-COPPE, Universidade Federal do Rio de Janeiro, Rio de Janeiro, 2014. Disponível em: <http://objdig.ufrj.br/60/teses/ coppe_m/PatriciaGomesFerreiraDaCosta.pdf $>$. Acesso em: 12 jun. 2014.

DANIELLOU, F. Métodos em ergonomia da concepção: a análise de situações de referência e a simulação do trabalho. In: DUARTE, F. (Org.). Ergonomia e projeto na indústria de processo contínuo. 1. ed. Rio de Janeiro: COPPE; New York: Lucerne Publishing, 2002. cap. 3. p. 29-33.

DANIELLOU, F.; BÉGUIN, P. Metodologia da ação ergonômica: abordagem do trabalho real. In: FALZON, P. Ergonomia. 1. ed. São Paulo: Blücher, 2007. cap. 20. p. 281-301.

DANIELLOU, F.; SIMARD, M.; BOISSIÈRES, I. Fatores humanos e organizacionais da segurança industrial: um estado da arte. Tradução Marlene Machado Zica Vianna; revisão técnica Raoni Rocha, Francisco de Paula Antunes Lima e Francisco José de Castro Moura Duarte. Toulousse: FonCSI, 2013. (Les cahiers de la sécurité industrielle, 2013-07).

DELTOR, S.; GUÉRIN, F. Intentions, modalités et démarche d'évaluation des diagnostics. In: BOUTERRIN, C.; DELTOR, S.; GUÉRIN, F. (Org.). Évaluation du diagnostic court: pour une évolution des pratiques et une plus grande efficacité de l'action. França: ANACT, 1994. p. 3-6. (Le Cahiers de L'ANACT, 1).

DUARTE, F. J. C. M. A análise ergonômica do trabalho e a determinação de efetivos: estudo da modernização tecnológica de uma refinaria de petróleo no Brasil. 2014. 134 p. Tese (Doutorado em Engenharia de Produção)-COPPE, Universidade Federal do Rio de Janeiro, Rio de Janeiro, 1994.

DUARTE, F. J. C. M.; VIDAL, M. C. Uma abordagem ergonômica da confiabilidade e a noção de modo degradado de funcionamento. In: FREITAS, C. M.; PORTO, M. F. S.; MACHADO, J. M. H. (Org.). Acidentes industriais ampliados: desafios e perspectivas para o controle e a prevenção. Rio de Janeiro: Fiocruz, 2000. cap. 2. p. 83-105.

ESPINOLA, A. Ouro Negro: petróleo no Brasil de Lobato Dnpm - 163 a Tupi Rjs - 646. 1. ed. Rio de Janeiro: Interciência, 2013.

FALZON, P. Ergonomia. 1. ed. São Paulo: Blücher, 2007.

FERREIRA, L. L. O trabalho dos petroleiros. In: DUARTE, F. (Org.). Ergonomia e projetos nas indústrias de processo contínuo. Rio de Janeiro: COPPE; New York: Lucerne Publishing, 2002. cap. 5. p. 64-74. 
FIGUEIREDO, M. G. Segurança e condições de trabalho nas plataformas de petróleo da Bacia de Campos. In: ENEGEP: A ENGENHARIA DE PRODUÇÃO E O FUTURO DO TRABALHO 18., 1998, Niterói. Anais... Rio de Janeiro: ABEPRO, 1998.

FLUSSER, V. Filosofia da caixa preta: ensaios para uma futura filosofia da fotografia. Apresentação de Norval Baitello Junior. São Paulo: Annablume, 2011.

GOLDENSTEIN, M. Desvendar e conceber a organização do trabalho: uma contribuição da ergonomia para o projeto de modernização de uma refinaria de petróleo. 1997. 129 p. Dissertação (Mestrado em Engenharia de Produção)-COPPE, Universidade Federal do Rio de Janeiro, Rio de Janeiro, 1997.

GUÉRIN, F. et al. Comprendre le travail pour le transformer: la pratique de l'ergonomie. France: ANACT, 1997. (Collection outils et methodes.).

HOLLNAGEL, E.; WOODS, D. D. Prologue: resilience engineering concepts. In: HOLLNAGEL, E.; WOODS, D. D. Resilience engineering: concepts and precepts. Hampshire: Ashgate Publishing Limited, 2006. p. 1-6.

HUBAULT, F. Do que a ergonomia pode fazer análise?. In: DANIELLOU, F. (Org.). A ergonomia em busca de seus princípios: debates epistemológicos. São Paulo: Edgard Blücher, 2004. p. 105-140.

INTERNATIONAL LABOUR OFFICE; INTERNATIONAL ERGONOMICS ASSOCIATION. Ergonomic checkpoints: practical and easy-toimplement solutions for improving safety, health and working conditions. 2. ed. Geneva, 2010.

KERBAL, A. La genèse du mode dégradé en milieu industriel. Le Travail Humain, Paris, v. 53, n. 4, p. 369372, 1990.

LEPLAT, J.; TERSSAC, G. Les facteurs humains de la fiabilité dans les systèmes complexes. Marseille: Editions Octares, 1990.

LLORY, M.; MONTMAYEUL, R. $O$ acidente e $a$ organização. Belo Horizonte: Fabrefactum, 2014.

MCATAMNEY, L.; CORLETT, E. N. RULA: a survey method for the investigation of work-related upper limb disorders. Applied Ergonomics, Guildford, v. 24, n. 2, p. 91-99, 1993. http://dx.doi.org/10.1016/00036870(93)90080-S. PMid:15676903.

NATIONAL COMMISSION ON THE BP DEEPWATER HORIZON OIL SPILL AND OFFSHORE DRILLING.

Deepwater: the gulf oil disaster and the future of offshore drilling - report to the presidente.

Washington: GPO, 2011. Disponível em: <http://www. gpo.gov/fdsys/pkg/GPO-OILCOMMISSION/pdf/GPOOILCOMMISSION.pdf>. Acesso em: 21 maio 2014.

PENTEADO, E., et al. Trabalho complexo e degradado: a realidade de uma unidade de terapia intensiva de um hospital público no Rio de Janeiro. In: ENEGEP:
A ENGENHARIA DE PRODUÇÃO E O FUTURO DO TRABALHO 18., 1998, Niterói. Anais... Rio de Janeiro: ABEPRO, 1998.

PERROW, C. B. Normal acidentes: living with high risk technologies. New York: Basic Books, 1984.

PORTO, M. F. S.; FREITAS, C. M. Aspectos sociais e qualitativos nas análises de causas de acidentes industriais em sistemas tecnológicos complexos. Revista Produção, Belo Horizonte v. 7, n. 1, p. 33-55, jul. 1997.

ROCHA, M. M. O modo degradado de funcionamento em sistemas de produção offshore. 2014. 110 p. Dissertação (Mestrado em Engenharia de Produção)COPPE, Universidade Federal do Rio de Janeiro, Rio de Janeiro, 2014. Disponível em: < http://objdig.ufrj. br/60/teses/coppe_m/MarcelaMartinsRocha.pdf $>$. Acesso em: 28 jun. 2014.

ROCHLIN, G. I.; LA PORTE, T. R.; ROBERTS, K. $\mathrm{H}$. The self-designing high-reliabitity organization: aircraft carrier flight operations at sea. Naval War College Review, Newport, v. 51, n. 3, p. 33-68, 1998.

SAGAR, M.. La conduite des dispositifs automatisés fonctionnant en mode dégradé: modele théorique et methodologique d'analyse. 1989. 277 p. Tese de (Doutorado em Ergonomia)-Conservatoire National des Arts et Métiers, França, 1989.

SILVA, G. C. C. Abordagem ergonômica em PMEs: um estudo de caso numa indústria de pneus remoldados. 2007. 191 p. Dissertação (Mestrado em Engenharia de Produção)-COPPE, Universidade Federal do Rio de Janeiro, Rio de Janeiro, 2007. Disponível em: < http://teses.ufrj.br/COPPE_M/ GislaineCyrinoCapistranoDaSilva.pdf $>$. Acesso em: 18 maio 2012.

THEUREAU, J. O curso da ação método elementar: ensaio de antropologia enativa e concepção ergonômica. Belo Horizonte: Fabrefactum, 2014.

VAUGHAN, D. The trickle-down effect: policy decisions, risky work, and the challenger tragedy. California Management Review, Berkeley, v. 39, n. 2, p. 80-102, 1997. http://dx.doi.org/10.2307/41165888.

. Theorizing disaster. Analogy, historical ethnography, and the challenger accident. Ethnography, London, v. 5, n. 3, p. 315-347, 2004. http://dx.doi.org/10.1177/1466138104045659.

VINCENTI, B. Diagnostic court: enjeux et contraintes. França: ANACT, 1994. p. 11-16. (Le Mensuel de L'ANACT, 195).

WEICK, K. E.; SUTCLIFFE, K. M. Managing the unexpected: resilient performance in an age of uncertainty. 2. ed. Hobokey: John Wiley \& Sons, 2007.

WISNER, A. La nouvelle usine en pays en développement industriel: transfert ou nouvelle 
conception. Le Travail Humain, Paris, v. 52, n. 3, p. 232-246, 1989.

. O trabalhador diante dos sistemas complexos e perigosos. In: . A inteligência no trabalho:

textos selecionados de ergonomia. São Paulo:

Fundacentro, 1994. p. 53-70.
WYNNE, B. Risk assessment of technological system: dimensions of uncertainty. In: (Org.). Risk management and hazardous waste: implementation and dialectics of credibility. Berlin: Springer-Verlag, 1987. p. 356-398. http://dx.doi.org/10.1007/978-3-64283197-3 11. 